\title{
HUBUNGAN PERUBAHAN SOSIAL EKONOMI PENGHUNI DENGAN PERUBAHAN LOKASI DAN KARAKTERISTIK HUNIAN (STUDI KASUS RUSUNAWA PULOGEBANG)
}

\author{
Sutikno Diharjo ${ }^{1}$ \\ ${ }^{1}$ Mahasiswa Program Magister Teknik Perencanaan, Universitas Tarumanagara, Jakarta \\ Surel: sutiknodiharjo@gmail.com
}

\begin{abstract}
Pulo Gebang rented vertical housing (Rusunawa) which was opened in 2013 became a place for low-income citizens from various locations in Jakarta to relocate to. In reality, post-relocation, changes in occupants' socio-economic conditions, such as job loss, low employment opportunities, or former jobs being far away, resulted in a decrease of income or increasing spending, as well as changing interactions and social kinship due to the new communities. Theoretically, several studies have shown that relocation results in changes in location and housing characteristics. Several other studies also showed that relocation results in changes in socio-economic aspect of occupants. This study aims to determine the socio-economic changes of residents after relocation to Rusunawa Pulo Gebang and their relationship with changes in location and characteristics of occupancy. The result of comparative analysis shows that there are significant changes in the socio-economic variables of the occupants, where of the 14 variables, 7 variables were proven to experience a decrease while 2 variables experienced an increase. In addition, there were significant changes in location and characteristics of occupancy, where of the 18 variables, it was proven that 7 variables experienced a decrease while 6 variables experienced an increase. Correlation analysis result shows that there is a significant relationship between changes in location and characteristics of occupancy and socio-economic changes, where 6 variables are associated with changes in occupant participation in community groups, 2 variables are associated with changes in family income and 2 variables are associated with changes in family expenditure.
\end{abstract}

Keywords: change, socioeconomic, location, residential characteristics, relocation.

\begin{abstract}
ABSTRAK
Rusunawa Pulo Gebang yang diresmikan pada 2013 menjadi wadah relokasi bagi MBR dari berbagai lokasi di Jakarta. Pada kenyataannya, pasca relokasi terjadi perubahan kondisi sosial ekonomi penghuni, seperti hilangnya pekerjaan, rendahnya peluang kerja atau jauhnya pekerjaan lama yang berdampak pada penurunan penghasilan atau peningkatan pengeluaran, serta perubahan interaksi dan kekerabatan sosial karena merupakan komunitas baru. Secara teoritis, beberapa penelitian memperlihatkan bahwa relokasi mengakibatkan terjadinya perubahan lokasi dan karakteristik hunian. Dalam beberapa penelitian lain juga memperlihatkan relokasi mengakibatkan terjadinya perubahan sosial ekonomi penghuni. Penelitian ini bertujuan untuk mengetahui perubahan sosial ekonomi penghuni pasca relokasi ke Rusunawa Pulo Gebang serta hubungannya dengan perubahan lokasi dan karakteristik hunian. Hasil analisis komparatif memperlihatkan bahwa terdapat perubahan signifikan pada variabel sosial ekonomi penghuni, dimana dari 14 variabel terbukti 7 variabel mengalami penurunan sedangkan 2 variabel mengalami peningkatan. Selain itu, terdapat perubahan signifikan lokasi dan karakteristik hunian, dimana dari 18 variabel terbukti 7 variabel mengalami penurunan sedangkan 6 variabel mengalami peningkatan. Hasil analisis korelasi memperlihatkan bahwa terdapat hubungan yang signifikan antara perubahan lokasi dan karakteristik hunian dengan perubahan sosial ekonomi, dimana 6 variabel berhubungan dengan perubahan partisipasi penghuni dalam kelompok komunitas, 2 variabel berhubungan dengan perubahan penghasilan keluarga dan 2 variabel berhubungan dengan perubahan pengeluaran keluarga.
\end{abstract}

Kata kunci: perubahan, sosial ekonomi, lokasi, karakteristik hunian, relokasi.

\section{PENDAHULUAN}

Penyediaan hunian di Indonesia masih menjadi masalah utama terutama di kota besar dengan fenomena urbanisasi yang tinggi. Hal ini disebabkan oleh terbatasnya ketersediaan lahan dan tingginya harga tanah. Masyarakat benghasilan rendah (MBR) memiliki akses terkecil untuk memenuhi huniannya karena ketidakmampuan keuangan. Salah satu solusi penyediaan hunian di 
kota besar adalah dengan pendekatan hunian vertikal. Menurut Kuswartojo (2005), penyediaan perumahan bagi kelompok MBR bermula pada akhir 1970-an hingga awal 1980-an dengan hunian tapak (landed house). Upaya pemerintah mengembangkan hunian vertikal baru dimulai pada tahun 1990-an, yaitu pembangunan hunian vertikal Kebon Kacang di Jakarta Pusat, menggantikan permukiman kumuh di lokasi yang ada. Program ini kemudian diikuti oleh berbagai lokasi lain di Jakarta. Pembangunan perumahan vertikal atau rumah susun empat lantai pada waktu itu dianggap sebagai solusi yang menjanjikan untuk mengatasi masalah perumahan, terutama di kota-kota besar, kota metropolitan seperti Jakarta, di mana harga tanah sangat mahal.

Saat ini, pembangunan dan penghunian hunian vertikal di Jakarta menjadi salah satu program utama Pemerintah DKI Jakarta. Hal ini dilakukan dalam rangka pengendalian banjir dan pemberantasan kekumuhan. Pemerintah melakukan serangkaian upaya, diantaranya adalah dengan merelokasikan sejumlah warga yang berada di bantaran sungai dan di permukiman kumuh. Salah satu hunian vertikal yang dibangun oleh Pemerintah DKI Jakarta adalah Rusunawa Pulo Gebang, sebagai salah satu hunian vertikal untuk mewadahi masyarakat dari berbagai lokasi permukiman kumuh dan bantaran sungai.

Rusunawa Pulo Gebang diresmikan pada 9 September 2013. Warga yang direlokasi ke Rusunawa Pulo Gebang ini meliputi warga dari berbagai lokasi di Jakarta dengan total mencapai 703 kepala keluarga. Faktanya, berdasarkan hasil survei awal yang dilakukan melalui wawancara dengan UPT Rusunawa Pulo Gebang, terdapat sejumlah fenomena pasca relokasi warga dari bantaran sungai dan permukiman kumuh. Terdapat beberapa permasalahan yang terjadi pada penghuni Rusunawa Pulo Gebang pasca relokasi, yaitu adanya perubahan kondisi sosial ekonomi penghuni Rusunawa Pulo Gebang. Hal ini diindikasi sebagai akibat dari perubahan lokasi hunian dan karakteristik hunian.

Permasalahan terkait kondisi perekonomian penghuni diindikasi dari warga yang menunggak pembayaran sewa unit rusunawa dengan jumlah yang tidak sedikit. Saat ditelusuri lebih lanjut, kondisi tersebut terjadi karena cukup banyak warga yang kehilangan pekerjaan karena berpindah lokasi, sulitnya mencari pekerjaan baru karena lokasi baru relatif kurang strategis dibanding lokasi sebelumnya, bekerja pada sektor informal dengan penghasilan yang tidak tetap maupun tetap bekerja di lokasi sebelumnya namun karena jarak dan waktu tempuh yang jauh sehingga kehilanga $\mathrm{n}$ banyak waktu dan biaya untuk transportasi. Dari pengamatan lokasi, hal tersebut dapat dipahami mengingat lokasi Rusunawa Pulo Gebang relatif berada di pinggir kota dan kurang strategis dibanding berbagai lokasi hunian warga sebelumnya yang berada di pusat kota dan lebih strategis.

Selain permasalahan ekonomi, terdapat permasalahan sosial yang diindikasi terjadi di Rusunawa Pulo Gebang pasca relokasi. Sebagai lokasi hunian baru dengan komunitas baru, masih ada beberapa warga yang belum secara baik berinteraksi dengan tetangga maupun mengikuti berbagai kegiatan komunitas. Bahkan diindikasi beberapa warga belum mengenal tetangga baik tetangga di sekitarnya. Padahal pengelola Rusunawa Pulo Gebang sudah berupaya secara rutin memfasilitasi kegiatan komunitas untuk meningkatkan hubungan dan interaksi antar penghuni. Permasalahan sosial tersebut dapat dipahami mengingat penghunian Rusunawa Pulo Gebang relatif masih baru (sekitar 4 tahun) dengan penghuni dari berbagai lokasi dan latar belakang sosial yang berbeda-beda.

Penelitian ini secara umum bertujuan untuk mengetahui perubahan aspek sosial ekonomi penghuni rusunawa Pulo Gebang serta perubahan lokasi dan karakteristik hunian yang terjadi 
pasca relokasi dan hubungan antara perubahan sosial ekonomi dengan perubahan lokasi dan karakteristik hunian. Adapun pertanyaan penelitian ini yaitu:

1. Apakah terdapat perubahan sosial dan ekonomi yang terjadi pada penghuni rusunawa Pulo Gebang pasca relokasi?

2. Bagaimana perubahan lokasi dan karakteristik hunian yang terjadi pada penghuni rusunawa Pulo Gebang pasca relokasi?

3. Apakah terdapat hubungan perubahan lokasi dan karakteristik hunian dengan perubahan sosial dan ekonomi pada penghuni rusunawa Pulo Gebang pasca relokasi?

Melalui penelitian ini diharapkan dapat merekomendasikan langkah-langkah yang perlu diambil baik sektor publik maupun swasta, sehingga dalam melakukan relokasi terhadap warga pada bantaran sungai dan perkampungan kumuh tidak lagi menuai sejumlah permasalahan. Selain itu, secara teoritis penelitian ini diharapkan dapat berkontribusi dalam menguji teori perubahan sosial ekonomi yang berkorelasi oleh perubahan lokasi dan karakteristik hunian.

\section{METODE PENELITIAN}

Menurut kamus besar bahasa Indonesia (1996), secara harafiah relokasi diartikan sebagai pemindahan tempat atau pemindahan dari suatu lokasi ke lokasi lain. ${ }^{1}$ Jika dikaitkan dalam konteks perumahan dan permukiman relokasi dapat diartikan pemindahan suatu lokasi permukiman ke lokasi permukiman yang baru. Menurut Hudohusodo (1989), relokasi dilakukan terhadap permukiman lokasi permukiman yang tidak diperuntukkan bagi perumahan atau lokasi permukiman yang rawan terhadap bencana atau bahkan yang terkena bencana. Berdasarkan definisi yang dikemukakan oleh World Bank (2010), relokasi merupakan prosesdimana perumahan dan infrastruktur publik sebuah komunitas dibangun kembali di lokasi yang berbeda.

Menurut De Jong \& Gardner (1981), relokasi perlu memperhatikan lokasi dan kualitas tempat relokasi baru adalah faktor penting dalam perencanaan relokasi, karena sangat menentukan kemudahan menuju ke lahan usaha, jaringan sosial, pekerjaan, bidang usaha, kredit dan peluang pasar. ${ }^{2}$ Setiap lokasi mempunyai keterbatasan dan peluang masing-masing. Memilih lokasi yang sama baik dengan kawasan yang dahulu (tempatnya yang lama) dari segi karakteristik lingkungan, sosial, budaya dan ekonomi akan lebih memungkinkan relokasi dan pemulihan pendapatan berhasil. Idealnya, tempat relokasi baru sebaiknya secara geografis dekat dengan tempat lama/ asli untuk mempertahankan jaringan sosial dan ikatan masyarakat yang sudah baik. Dalam proyek pembangunan perkotaan, yang sering mengakibatkan relokasi dalam jumlah besar, dampak tersebut dapat dikurangi dengan merelokasikan ke berbagai kawasan yang kecil dan dekat. Dalam kasus tersebut, pemilihan tempat dan rencana relokasi harus berdasarkan, dan diputuskan melalui musyawarah dengan masyarakat. Kepada masyarakat, disampaikan informasi tentang calon lokasi dan diberi kesempatan untuk meninjau lokasi yang sudah dibangun sebelum secara resmi diserahkan. Hal ini diperlukan agar masyarakat dapat menentukan pilihannya secara bebas.

Menurut De Jong \& Gardner (1981), masalah relokasi berkaitan erat dengan masalah ekonomi dan sosial budaya, di samping masalah pemulihan kondisi psikologis. Oleh karena itu, berkaitan dengan bentuk rumah dan bangunan lain yang relevan agar dikonsultasikan dengan 
masyarakat yang akan dipindahkan agar sesuai dengan keinginan penghuni. Bila dikaitkan dengan teori perumahan oleh O'Sullivan, maka perubahan karakteristik hunian dapat berupa perubahan ukuran; perubahan bentuk/layout; perubahan utilitas; perubahan desain interior; dan perubahan kesatuan struktur. Berdasarkan beberapa kajian teoritis tersebut, maka dalam penelitian ini aspek perubahan karakteristik hunian sebagai akibat dari proses relokasi di Rusunawa Pulo Gebang yaitu luas hunian, jumlah kamar tidur, kualitas hunian, ketersediaan listrik, ketersediaan air bersih, kualitas air bersih, dan kualitas pengelolaan sampah.

Dampak sosial adalah perubahan dalam kondisi kehidupan orang-orang yang terjadi bersama dengan suatu kebijakan yang baru, program atau proyek. Masalah utama dari relokasi adalah kehilangan masyarakat atas mata pencaharian serta penurunan kemampuan potensial mereka akibat dari pemindahan tersebut. Ketika suatu komunitas terpaksa untuk pindah maka system produksi yang sudah ada menjadi berkurang. Banyak pekerjaan, lahan yang bernilai, serta asset pendapatan yang hilang. Kelompok kekerabatan serta jaringan sosial informal yang tercerai berai. Resiko yang paling sering dihadapi oleh penduduk bantaran sungai yang permukimannya harus dipindahkan adalah kehilangan lahan, kehilangan pekerjaan, kehilangan hunian, kehilangan terhadap akses produksi dan disartikulasi komunikasi. Menurut De Wet (2002), hasil yang diharapkan dari proses relokasi adalah agar kondisi masayarakat yang direlokasi menjadi lebih baik dari kondisi sebelum terjadi relokasi. ${ }^{3}$ Kondisi yang lebih baik tersebut sebaiknya bertahan lama dari waktu ke waktu agar pada lokasi permukiman yang baru dapat tumbuh menjadi permukiman yang nyaman. kondisi yang lebih baik tersebut meliputi: tingkat pendapatan, keberagaman sumber pendapatan, status dan jaminan di lokasi yang baru, akses terhadap pelayanan infrastruktur dasar.

Pemukiman kembali bukan hanya suatu proses pemindahan orang-orang dari suatu lokasi, akan tetapi juga memindahkan perilaku dan identitas - identitas dari orang-orang tersebut. Menurut Finsterbusch, Kurt \& Motz (1981), individu-individu atau masyarakat merasakan dampak dari suatu kebijakan dalam 5 kategori, yaitu: ${ }^{4}$

a. Secara ekonomi, sebagai pekerja yang kehilangan atau mendapatkan penghasilan maupun pekerjaan.

b. Secara lingkungan, sebagai penduduk yang habitatnya di ubah atau disita.

c. Secara transportasi, sebagai pengendara atau penikmat jasa transportasi yang kehilangan aksesibilitas.

d. Secara sosial, sebagai kerabat, teman anggota, yang pola sosialnya berubah.

e. Secara psikologi, sebagai individu yang mengalami stress, ketakutan, perampasan dan lainlain.

Berdasarkan hasil tinjauan teoritis yang dilakukan, dapat dirumuskan hipotesis penelitian sebagai berikut:

a. Hipotesis 1: Terdapat perubahan yang signifikan kondisi sosial ekonomi penghuni serta lokasi dan karakteristik hunian antara sebelum dan sesudah relokasi ke rusunawa Pulo Gebang.

b. Hipotesis 2: Terdapat hubungan antara partisipasi penghuni dalam kelompok komunitas dengan perubahan aspek sosial lingkungan akibat perubahan lokasi hunian.

c. Hipotesis 3: Terdapat hubungan antara perubahan penghasilan keluarga dengan perubahan aspek ekonomi keluarga akibat perubahan lokasi hunian.

d. Hipotesis 4: Terdapat hubungan antara perubahan pengeluaran keluarga dengan perubahan lokasi dan karakteristik hunian. 
Jenis penelitian ini merupakan penelitian kuantitatif yang termasuk dalam bentuk penelitian survei deskriptif. Variabel penelitian yang dirumuskan sebanyak 32 variabel yang meliputi 8 variabel sosial penghuni, 6 variabel ekonomi penghuni, 11 variabel lokasi hunian dan 7 variabel karakteristik hunian. Dengan obyek penelitian penghuni Rusunawa Pulogebang, ditentukan jumlah sampel sebesar 100 keluarga yang dipilih menggunakan metode proportionate stratified random sampling dengan pendekatan proporsional dari lokasi asal penghuni sebelum direlokasi ke Rusunawa Pulogebang. Teknik analisis korelasi dipilih sebagai metode analisis mengingat tujuan penelitian untuk mengetahui hubungan antara variabel bebas terhadap variabel terikat.

\section{HASIL DAN PEMBAHASAN}

Rusunawa Pulo Gebang mulai dibangun pada tahun 2007 dan selesai tahun 2009, namun baru pada tahun 2013 diresmikan dengan pemanfaatannya untuk tempat tinggal hasil relokasi warga di bantaran sungai dan permukiman kumuh. Penghuni Rusunawa Pulo Gebang paling banyak merupakan hasil relokasi dari Kali Item dengan jumlah $160 \mathrm{KK}$, diikuti oleh hasil relokasi dari Penjaringan dengan $103 \mathrm{KK}$.

Bangunan Rusunawa pada umumnya terdiri dari 6-8 lantai, di mana di lantai dasar merupakan bangunan dengan fungsi utama adalah untuk usaha dengan fungsi pendukung lainnya adalah kantor dan gudang, sementara untuk lantai ke-2 sampai dengan ke-6 atau ke-8 merupakan bangunan dengan fungsi hunian. Di tengah-tengah bangunan terdapat void sebagai bagian dari sirkulasi udara dan pencahayaan. Untuk akses penghuni ke atas ataupun ke bawah bangunan, telah disediakan tangga dan lift. Dalam skala yang lebih kecil, yaitu Satuan Rumah Susunya (Sarusun), tiap unit sarusun memiliki luas $36 \mathrm{~m} 2$. Komposisi ruang dari tiap sarusun adalah: 2 ruang tidur, 1 ruang tamu, 1 ruang dapur, 1 ruang kamar mandi, dan 1 ruang lain yang bisa dimanfaatkan untuk menjemur pakaian.

Rusunawa Pulo Gebang memiliki cukup banyak fasilitas pelayanan untuk para penghuninya. Sejumlah fasilitas yang dapat dinikmati warga, mulai dari fasilitas pendidikan, kesehatan, tempat bermain anak, hingga sarana transportasi. Sementara dari sisi utilitas, dapat diketahui bahwa penyediaan air bersih dilakukan dengan menggunakan skema penyediaan melalui PAM dan air tanah; kebutuhan listrik dilayani oleh PLN melalui jaringan udara; untuk pengolahan air limbah dari rumah tangga telah terdapat STP (Sewage Treatment Plant), untuk limpasan air hujan telah terdapat jaringan tersier dan sekunder yang terhubung dengan saluran perkotaan; dalam pengelolaan sampah telah disediakan tempat sampah lingkungan, serta tempat penampungan sampah di tiap blok rusunawa yang dihubungkan dengan seluruh lantai; dan untuk mengantisipasi kebakaran yang mungkin terjadi, maka di setiap blok rusunawa, telah disiapkan hidran umum.

Dari hasil pendataan lapangan, dapat diketahui bahwa responden umumnya merupakan penduduk berusia produktif, dan kepala keluarga umumnya tidak berada di rumah karena sedang ada aktivitas di luar rumah. Sebagaimana diketahui, survei dilakukan bukan saat hari kerja pada umumnya. Ditinjau dari karakteristik keluarga penghuni, dapat diketahui bahwa bahwa pada umumnya tiap sarusun diisi oleh satu keluarga yang telah tinggal lebih dari 3 tahun, terdiri dari sepasang suami istri dengan anggota keluarga lainnya (1-4 orang) baik itu anak dan/atau saudaranya. Kepala keluarga sendiri pada umumnya berusia produktif, namun hanya memiliki tingkat pendidikan SMA atau sederajat.

Berdasarkan hasil analisis komparatif, variabel sosial ekonomi penghuni yang mengalami perubahan pasca relokasi di Rusunawa adalah: 
1. tingkat kenal tetangga, interaksi dengan tetangga sehari-hari, dan panutan/tokoh masyarakat di lingkungan dengan kecenderungan penurunan. Hal ini diindikasi karena lokasi hunian baru di Rusunawa Pulo Gebang dengan komunitas baru dan lama tinggal paling lama 4 tahun (masih baru), membuat sebagian penghuni belum banyak mengenal tetangga, interaksi dengan tetangga masih lebih rendah dan belum munculnya panutan/tokoh masyarakat, dibandingkan pada lokasi hunian lama.

2. pengelompokan sosial dalam pemilihan hunian dengan kecenderungan peningkatan. Hal ini diindikasi karena pada Rusunawa Pulo Gebang pemilihan hunian ditentukan berdasarkan asal lokasi tinggal sebelumnya, hal ini berbeda dengan kondisi di hunian lama dimana pemilihan hunian sesuai ketersediaan hunian dan kemampuan penghuni bukan atas pengelompokan sosial.

3. penurunan pekerjaan kepala keluarga, penurunan jumlah anggota dalam keluarga yang bekerja, peningkatan waktu tempuh ke tempat kerja, penurunan transportasi yang digunakan ke tempat kerja, dan penurunan penghasilan keluarga. Hal ini memperlihatkan bahwa kepindahan penghuni ke Rusunawa Pulo Gebang dari berbagai lokasi yang memiliki nilai strategis dan kedekatan dengan pusat kegiatan, berdampak pada penurunan kondisi perekonomian keluarga karena secara lokasi berada di pinggir kota dan kurang didukung dengan ketersediaan pekerjaan yang dibutuhkan penghuni.

Berdasarkan hasil analisis komparatif, variabel lokasi dan karaktersitik hunian yang mengalami perubahan pasca relokasi di Rusunawa adalah:

1. nilai strategis lokasi hunian, kemudahan pencapaian ke lokasi, dan kedekatan dengan pusat kegiatan dengan kecenderungan menurun. Hal ini dinilai wajar, mengingat lokasi Rusunawa Pulo Gebang yang berada di pinggir kota, sedangkan sebagian besar penghuni berasal dari lokasi di pusat kota yang memiliki nilai strategis, lebih mudah dicapai dan lebih dekat dengan pusat-pusat kegiatan.

2. kualitas hunian, kualitas pengelolaan sampah, kualitas fasilitas kesehatan, fasilitas ruang terbuka, kondisi kebersihan lingkungan dan kondisi keasrian lingkungan dengan kecenderungan peningkatan. Hal ini memperlihatkan bahwa keempat hal tersebut sudah berhasil dilakukan perbaikan/peningkatan kualitas dari kondisi pada hunian lama.

3. kualitas air bersih, kualitas fasilitas pendidikan, fasilitas komersial, dan kondisi keamanan lingkungan dengan kecenderungan penurunan. Hal ini memperlihatkan bahwa keempat hal tersebut masih menjadi permasalahan yang perlu diperbaiki/ditingkatkan oleh pengelola Rusunawa Pulo Gebang dan Pemerintah Provinsi DKI Jakarta.

Berdasarkan hasil analisis korelasi, faktor-faktor yang perlu dipertimbangkan dalam melakukan relokasi ke Rusunawa, adalah:

1. faktor yang berhubungan signifikan dengan perubahan partisipasi dalam kelompok komunitas, yaitu tingkat kenal tetangga, interaksi dengan tetangga sehari-hari, rutinitas kegiatan komunitas, partisipasi warga dalam kegiatan komunitas, panutan/tokoh masyarakat di lingkungan, dan pengelompokan sosial dalam pemilihan hunian. Hal ini memperlihatkan bahwa penghuni cenderung berpartisipasi dalam kelompok komunitas apabila mengenal dengan tetangga baik, berinteraksi baik dengan tetangga, adanya partisipasi warga lainnya, adanya panutan/tokoh masyarakat dan adanya pengelompokan sosial dalam hunian.

2. faktor yang berhubungan signifikan dengan perubahan penghasilan keluarga, yaitu perubahan jumlah anggota keluarga yang bekerja, dan perubahan persepsi kedekatan ke pusat kegiatan. Hal ini memperlihatkan bahwa untuk mengantisipasi perubahan penghasilan keluarga, maka proses penghunian warga ke Rusunawa perlu didukung dengan ketersediaan lapangan 
pekerjaan yang sesuai bagi penghuni atau pada lokasi dengan ketersediaan pusat kegiatan produktif, dalam jarak yang berdekatan dengan lokasi hunian.

3. faktor yang berhubungan signifikan dengan perubahan pengeluaran keluarga, yaitu persepsi kualitas transportasi dan persepsi nilai strategis lokasi. Hasil ini agak di luar perkiraan, karena ternyata tidak memiliki hubungan dengan kondisi hunian, kondisi fasilitas, dan kondisi lingkungan yang lebih baik. Subsidi yang diberikan oleh Pemerintah Provinsi DKI pada penghuni, seperti subsidi hunian, fasilitas, transportasi, dan pengelolaan lingkungan diindkasikan menyebabkan pengeluaran penghuni tidak terbebani.

\section{KESIMPULAN DAN SARAN}

Secara umum, hasil penelitian ini telah dapat menjawab 3 pertanyaan penelitian yang telah diuraikan pada Bab I. Pertama, terdapat perubahan signifikan pada aspek sosial ekonomi penghuni pasca menghuni Rusunawa Pulo Gebang. Dari 14 variabel sosial ekonomi, terbukti 9 variabel mengalami perubahan yang siginifikan, dimana 7 variabel mengalami penurunan sedangkan 2 variabel mengalami peningkatan. Kedua, terdapat perubahan lokasi dan karakteristik hunian penghuni pasca menghuni Rusunawa Pulo Gebang. Dari 18 variabel lokasi dan karakteristik hunian, terbukti 13 variabel mengalami perubahan yang signifikan, dimana 7 variabel mengalami penurunan sedangkan 6 variabel mengalami peningkatan. Ketiga, terdapat hubungan yang signifikan antara perubahan lokasi dan karakteristik hunian dengan perubahan sosial ekonomi penghuni pasca menghuni Rusunawa Pulo Gebang. Dimana, 6 variabel berhubungan dengan perubahan partisipasi penghuni dalam kelompok komunitas, 2 variabel berhubungan dengan perubahan penghasilan keluarga dan 2 variabel berhubungan dengan perubahan pengeluaran keluarga.

\section{REFERENSI}

De Jong, Gordon F \& Gardner, Robert W. (ed). 1981. Migration Decision Making. Multidisciplinary Approaches to Microlevel Studies in Developed and Developing Countries. New York: Pergamon Press.

De Wet, Chris. 2002. The Experience with Dams and Resettlement in Africa. Cape Town: World Commission on Dams, South Africa.

Finsterbusch, Kurt \& Motz. 1981. Public Housing and Social Research for Policy Decisions. California: Walsworth Publishing Company.

Kamus Besar Bahasa Indonesia Edisi Kedua. 1996. Jakarta: Balai Pustaka.

Tjuk, Kuswartojo. 2005. Perumahan dan pemukiman di Indonesia. Bandung: Institut Teknologi Bandung. 